\title{
Simulation-based Framework to Improve Patient Experience in an Emergency Department
}

Waleed Abo-Hamad

Technological University Dublin, waleed.abohamad@tudublin.ie

Amr Arisha

Technological University Dublin, amr.arisha@tudublin.ie

Follow this and additional works at: https://arrow.tudublin.ie/buschmarart

Part of the Business Commons

\section{Recommended Citation}

Abo-Hamad, Waleed, Arisha, Amr: Simulation-based framework to improve patient experience in an emergency department, European Journal of Operational Research, Volume 224, Issue 1, 1 January 2013, Pages 154-166, ISSN 0377-2217. http://dx.doi.org/10.1016/j.ejor.2012.07.028.

This Article is brought to you for free and open access by the School of Marketing at ARROW@TU Dublin. It has been accepted for inclusion in Articles by an authorized administrator of ARROW@TU Dublin. For more information, please contact arrow.admin@tudublin.ie, aisling.coyne@tudublin.ie,gerard.connolly@tudublin.ie.

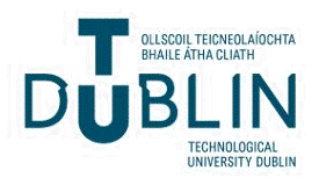




\title{
Simulation-based Framework to Improve Patient Experience in an Emergency Department
}

\author{
Waleed Abo-Hamad, Amr Arisha \\ 3S Group, College of Business \\ Dublin Institute of Technology \\ Dublin, Ireland
}

\begin{abstract}
The global economic crisis has a significant impact on healthcare resource provision worldwide. The management of limited healthcare resources is further challenged by the high level of uncertainty in demand, which can lead to unbalanced utilisation of the available resources and a potential deterioration of patient satisfaction in terms of longer waiting times and perceived reduced quality of services. Therefore, healthcare managers require timely and accurate tools to optimise resource utility in a complex and ever-changing patient care process. An interactive simulation-based decision support framework is presented in this paper for healthcare process improvement. Complexity and different levels of variability within the process are incorporated into the process modelling phase, followed by developing a simulation model to examine the impact of potential alternatives. As a performance management tool, balanced scorecard (BSC) is incorporated within the framework to support continual and sustainable improvement by using strategic-linked performance measures and actions. These actions are evaluated by the simulation model developed, whilst the trade-off between objectives, though somewhat conflicting, is analysed by a preference model. The preference model is designed in an interactive and iterative process considering decision makers preferences regarding the selected key performance indicators (KPIs). A detailed implementation of the framework is demonstrated on an emergency department (ED) of an adult teaching hospital in north Dublin, Ireland. The results show that the unblocking of ED outflows by in-patient bed management is more effective than increasing only the ED physical capacity or the ED workforce.
\end{abstract}

Keywords: Simulation; Multiple Criteria Decision Analysis, Emergency Department; Healthcare Management 


\section{Introduction}

Healthcare managers are constantly under pressure to control rapidly escalating expenses whilst simultaneously fulfilling the growing demand for healthcare services. As a result, they are continuously studying the efficiency of existing healthcare systems and exploring improvement opportunities. The evaluation of these proposed interventions is crucial prior to their actual implementation, though challenged by intrinsic uncertainty of demands and outcomes of healthcare systems; high level of human involvement at both patients level and resource level (doctor, nurses, etc.); limited budget and resources; and large number of variables (e.g., staff scheduling, number of beds, etc). Patients, on the other hand, in addition to requiring a high service quality, are understandably no longer prepared to wait in queues for essential health services. Accordingly, the healthcare service concept has shifted from optimising resources utilisation to finding a balance between service for patients and efficiency for providers (Brailsford \& Vissers, 2011). Dealing with these inevitable complexities within healthcare processes and services (e.g., hospitals, emergency departments, and bed management) and addressing the challenges in the decision making process is the focus of this paper.

Discrete-Event Simulation (DES) has proven to be an effective tool for process modelling and improvement (Benneyan, 1997; Jun, Jacobson, \& Swisher, 1999). Healthcare managers can apply DES for assessing current performance, predicting the impact of operational changes, and examining the tradeoffs between system variables (Wierzbicki, 2007). Furthermore, DES has been used to identify areas of improvement of service through possible reorganisation of existing resources, for example; reorganisation of surgical and anaesthesia care surrounding laparoscopic surgery (Stahl, et al., 2004); and planning for the geographical locations of new healthcare services taking into account the demographics of the population and the location of the patients who need the services (Harper, Shahani, Gallagher, \& Bowie, 2005). Furthermore, DES is well-suited to tackle problems in emergency departments (EDs), where resources are scarce and patients arrive at irregular times (Jun, et al., 1999), and effectively combine data mining (Ceglowski, Churilov, \& Wasserthiel, 2006) for better results. Though a substantial body of work has appeared in the literature, most of these papers do not use strategy-linked performance measures and actions. The development and application of a decision support system that can coordinate diverse staff categories toward the strategy direction is becoming more pivotal for strategy implementation (Voelker, Rakich, \& French, 2001). Moreover, the decision-maker 
preferences information is rarely considered in the process of alternative evaluation (Rosen, et al. 2008).

The objective of this paper is to develop an interactive simulation-based decision support framework to improve planning and efficiency of healthcare processes. A real-world case study of an emergency department in one of the largest University Hospitals in Dublin is investigated in order to enhance patients’ experience using the proposed framework.

\section{Proposed Integrated Framework}

\subsection{Literature review}

Efforts to develop DES models have been advancing since the late 1980s when Saunders et al. (Saunders, Makens, \& Leblanc, 1989) proposed a model to study the impact of key resources on waiting times and throughput. Since that time, DES models have been used to study the effect of a wide range of health interventions on healthcare processes' performance, for example; designing a new house staff work schedule (Dittus, Klein, DeBrota, Dame, \& Fitzgerald, 1996) and ambulance schedules (Ingolfsson, Erkut, \& Budge, 2003); improving capacity utilisation in intensive care units (S. C. Kim, Horowitz, Young, \& Buckley, 1999; Litvak, Van Rijsbergen, Boucherie, \& Van Houdenhoven, 2008); planning healthcare services (Oddoye, Jones, Tamiz, \& Schmidt, 2009); and evaluating different health interventions such as comparing the 'individual surgeons' strategy with the 'pooled lists' strategy for scheduling outpatient clinical appointments in surgical care (Vasilakis, Sobolev, Kuramoto, \& Levy, 2006).

Recently, calls for improved performance have grown significantly. Therefore, applications for operational decision support are widespread and have become increasingly significant (Eldabi, Paul, \& Young, 2006). Most of these undertakings have focussed on departmental operations; especially the more patient-intensive ones such as outpatient and emergency departments. For example, Samaha et al. (Samaha, Armel, \& Starks, 2003) analysed the effect of the physical expansion of ED on patient stay times. However, physician skills level was not considered in patients' service time. The impact of different patient triage methods on service times has been studied by (Connelly \& Bair, 2004). Yet, variations in patients' arrival rate were not considered. The effect of staffing levels were investigated by (Sinreich \& Jabali, 2007) to reduce patient's length of stay (LOS) and by (Ahmed \& Alkhamis, 2009) to determine the optimal number of required staff (e.g., doctors, lab technicians and nurses) that maximise patient throughput and to reduce patient experience 
time. In (Duguay \& Chetouane, 2007), a number of alternatives based on adding resources has been investigated with the objective to reduce patient waiting times and to improve overall service delivery and system throughput. Additionally, (Thorwarth, Arisha, \& Harper, 2009) examined the impact of staff scheduling on overall utilisation and burnout issues related to over-utilised staff. The tradeoffs between different alternatives such as adding more beds or altering the admission rate has been evaluated by (Khare, Powell, Reinhardt, \& Lucenti, 2009), where patient length of stay is considered as the key performance indicator (KPI). However, aforementioned studies only consider a small number of KPIs (e.g., waiting time and LOS), while other performance measures such as resource utilisation, productivity, and layout efficiency are rarely considered. Moreover, linking these KPIs to the international standard and national metrics is mostly neglected.

On the other hand, the balanced scorecard (BSC), pioneered by (Kaplan \& Norton, 1992), is a systematic methodology that uses strategy-linked leading and lagging performance measures and actions for planning and implementing an organization's strategy (Kaplan \& Norton, 2001). With many successful implementations at different organizations, BSC is considered as a popular model and effective means for performance management and strategy execution. Furthermore, the BSC concept has been modified and successfully developed at different types of healthcare organizations (Zelman, Pink, \& Matthias, 2003). The BSC usually has several perspectives (e.g., financial, internal operations, and patient) of the healthcare facility performance, with each perspective composed of main objectives and subobjectives.

Yet, these objectives are interacting among themselves simultaneously, influencing each other in a complex relationship network, often under conditions that involve randomness, and requires the observation and evaluation of numerous decision criteria. Therefore, a structured technique is needed for dealing with problems with multiple and complex criteria influencing decision making (Dyer, Fishburn, Steuer, Wallenius, \& Zionts, 1992; Liberatore \& Nydick, 2008; Saaty, 1990).

\subsection{An Interactive Simulation-based Decision Support Framework}

An overview of the framework is given in Figure 1 where a detailed description of each component is provided through the next sections. Further, the coordination between these components is explained in details along with highlighting their points of integration. 


\subsubsection{Formulation and Understanding}

Healthcare systems contain a high level of social interactions that are characterized by complexity and in particular at decision points. Therefore, problems associated with healthcare service delivery and managing patient flow are usually hard to define problems. Gaining a better understanding of the healthcare process is essential for making correct justifiable decisions and providing effective solutions. Therefore, it is necessary to formulate the underlined problem from the point of view of the individuals who are directly involved in the process of service delivery.

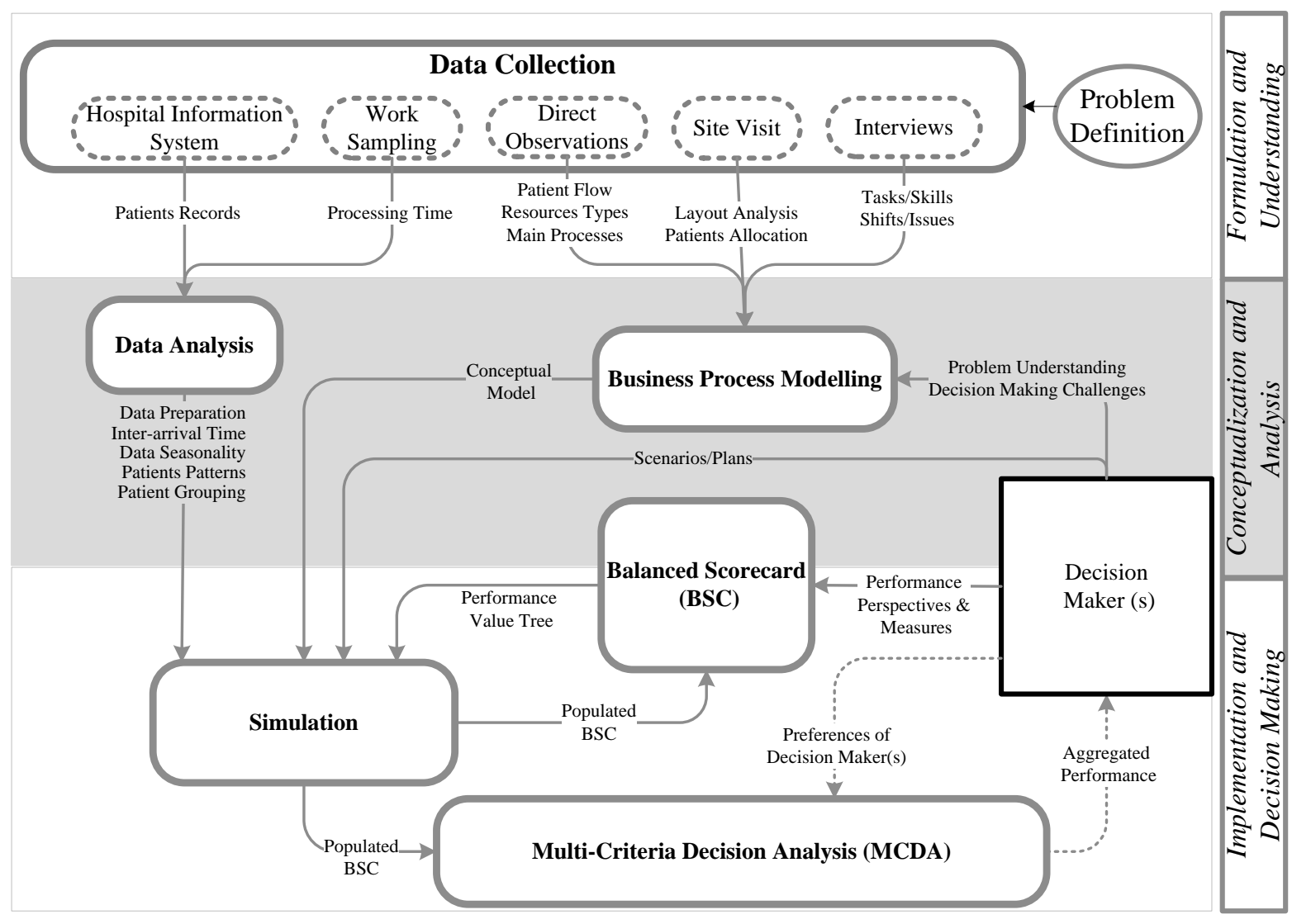

Figure 1 An interactive simulation-based decision support framework

Accordingly, the data collection phase proceeds to gather relevant information of the underlying processes. This phase focuses on the retrieval of the data and also on the construction of a conceptual model (i.e., business process model). The quantitative data is either stored in databases, written on documents, or recorded on any type of storage medium where the qualitative data can be obtained via direct observation of the system and interviews from the experts. In the healthcare context, experts are those who work in the hospital doctors, nurses, consultants, administrators and managers. 


\subsubsection{Conceptualizations and Analysis}

The data collection phase combines data from observations and interviews with experts and practitioners. This in return provided holistic insights for various system issues and aspects. The underlined business processes are then mapped into a conceptual process model using one of the well-developed modeling languages where sub-processes and activities are identified. The control flow definition is created by identifying the entities that flow through the system (e.g., patients, staff, and medical resources) and describing the connectors that link the different parts of the process. Finally, the resources are identified and assigned to the activities where necessary. The conceptual model is used in the simulation model for two purposes: first it is guidance for the actual simulation model, which contains and considers a higher degree of details, and second it is used as a communication platform in order to validate the model with the experts working within the real system. Once the conceptual model is completed, it is essential to validate it with the staff in the facility including senior managers. This is an essential step for the credibility of the simulation model and hence its output.

Interviews and observations have greatly contributed to a better understanding and an accurate modeling of work flow in the healthcare facility. However, to incorporate the time factor, patient's records are collected from the hospital information system (HIS), including information regarding patient care path, arrival time, mode of arrival, referral type, and time of discharge or admission. The patient's records are entered by different type of staff (e.g. administrators, doctors, and nurses through the stages of patients care). Due to the high level of pressures within healthcare processes, hospital records in many instances lack accuracy and consistency. Therefore, prior to extracting any set of data from these records, data mining procedures are required to extract the trustworthy set of records. This is followed by a further analysis of the resulting records for extracting patient arrival patterns, patient groups, distributions and seasonality features.

Planning, analysing, and evaluating the performance of any healthcare process are key elements for setting a comprehensive framework to support continual improvement. To transform objectives into a set of actions, managers need to set proper performance measures and set a realistic and achievable target for each objective. Mostly, the targets are stemmed from the national healthcare authorities (e.g., Health Service Executive (HSE) in Ireland and National Health Service (NHS) in the UK). The performance perspectives and performance measures collected through interviewing senior managers of the healthcare facility are used to 
develop a BSC for the healthcare facility. This is essential to align the performance measures of the healthcare facility (e.g., emergency department) with the strategic objectives of the national health authorities.

These measures are used to represent the output of the simulation model. Consequently, the simulation model will provide quantitative values of the provided performance measures where qualitative measures such as patient satisfaction can be related to measurable indicators such as average waiting time and LOS. Such integration allows the evaluation of a wide range of actions and plans based on the recommendations of national reports and surveys. These plans can then be evaluated in the form of what-if scenarios, with the results are used to populate the design BSC.

\subsubsection{Implementation and Decision Making}

Once the conceptual model is validated, the model translation phase begins, which combines the validated conceptual model and the results of the patients' records analysis. The simulation model can either be the programming of code, or modeling with the use of simulation software package, which provides the modeler with tools that are typical and essential for certain modeling. The procedure is often referred as model translation, because it describes the transformation of the abstract conceptual model into a higher detailed complex executable simulation model. Verification during the modeling phase ensures that the model logic reflects the underlying business process. The difference between verification and validation within the context of simulation modeling is that verification ensures that the transformation of the conceptual model has been applied correctly, where validation considers the representation of the model towards the system under investigation (Balci, 1997).

After the model verification and validation, the decision makers can use the model to investigate the impact of decisions and alternatives (i.e., what-if scenarios) to foresee the consequences of these decisions. The results can then be evaluated and interpreted by experts and decision makers, which provide guidance on the implementation of suggested alternatives and plans, as well as set benchmarks of the maximum performance that can be achieved using the available resources and staffing levels. Hence, more practical solutions and plans can be recommended and tested using the simulation model. Therefore, such integration between simulation and BSC helps to focus on strategic visions to obtain desired outcomes, assists in making better decisions, improves communication within the organization, provides continual feedback on strategies, promotes adjustments to changes and 
assists both individuals and organizations in achieving their goals and objectives. Moreover, the capabilities of the simulation can provide interesting information about the causal-effect relationships among performance.

However, the number of performance indicators (i.e., criteria) delays the evaluation and analysis of the simulation results. This is due to the fact that some of these criteria are of a conflicting nature and oppose each other. The trade-off between different objectives is analysed using multi-criteria decision analysis (MCDA) in an interactive and iterative process with senior managers. This is achieved by developing an aggregated preference model using preference ratios in multi-attribute evaluation (PRIME) (Salo \& Hamalainen, 2001). PRIME is able to handle incomplete information (i.e, uncertainty) about decision maker preferences through the use of interval-valued ratio statements (Lindstedt, Hämäläinen, \& Mustajoki, 2001). MCDA can also effectively aggregate the marginal performance of the indicators considering the preferences of the decision makers regarding the achievement of the defined strategic objective.

\subsection{Emergency Department - A Case Study}

Overcrowding in emergency departments (EDs) tends to be a significant international crisis that negatively affects patient safety, quality of care, and patient satisfaction (Graff, 1999). ED overcrowding has been declared as a "National Emergency" in Ireland since 2006. Several national reports have highlighted a growing demand for emergency care (1.2 million patients attending EDs annually) and a simultaneous decrease in the number of operating EDs. The result has increased crowding, high percentages of patients leaving EDs without being seen and higher morbidity and mortality rates. Additionally, prolonged waiting times has been reported with more than 500 patients on trolleys for hospital admission every day; $18 \%$ of patients are waiting more than 24 hours and $40 \%$ between 10-24 hours (HSE Performance Monitoring Report, 2010). Although Ireland is not alone in experiencing these kind of figures (Forero, et al., 2010; Rowe, et al., 2006; Schafermeyer \& Asplin, 2003), it is important not to underestimate the probable catastrophic consequences this situation has on patients, staff and healthcare sector across the State. Therefore, analysing the patient flow in emergency departments to minimize length of stay, improve efficiency, and reduce overcrowding has become a crucial requirement.

The hospital studied is a an acute, public, voluntary, and adult teaching hospital that holds a unique place in the delivery of healthcare not only to the community of North Dublin but also to the rest of Ireland. This 570-bed hospital provides primary, specialized, and 
tertiary healthcare services, with a 24hr “on-call” ED which services over 55,000 patients annually.

According to the task force report in 2007, the overall ED physical space and infrastructure is inadequate. Additionally, the hospital is operating at approximately 99\% occupancy with resultant difficulty in accommodating surges in numbers of ED admissions. This is often aggravated by delays in patients transfer to critical care (ICU/HDC) beds. Consequently, the hospital is not compliant with volume and wait time targets (6 hour patient experience time target). The ED figures show a clear evidence of overcrowding with $17 \%$ of patients leaving the ED before being seen on average. Moreover, the average time from registration to discharge is 9.16 hrs with 2.58 hrs standard deviation, i.e. 3.16 hrs over the HSE metric (0-6 hrs). Besides, the average time from registration to acute admission is 21.3 hrs with a standard deviation of 17.2 hrs, which is 15.3 hrs above the national metric. Obviously, patients to be admitted usually experience longer length of stay than discharged patients due to the delays that can occur between admission referral by ED doctor, bed allocation, and patient transferral from ED to the allocated bed.

The proposed framework is used to model the complexity of the ED to identify performance bottlenecks and to explore potential solutions that can lead to better performance and to meet the national metrics.

\section{Model Development}

\subsection{Emergency Department Layout}

The department has officially, 12 monitored trolley spaces; 3 of these trolley spaces (resuscitation area) are reserved for major trauma and critical care patients. Besides, the ED has a ambulatory car area with a capacity of six trolley spaces. Two isolation rooms, 1 psychiatric assessment room, two rapid assessment triage bays, and two triage rooms are also provided by the ED. There are 5 distinct areas in the ED (Figure 2): walk-in patient waiting room, X-Ray and CT scan area, ambulatory care area, ED resuscitation area, and ED major assessment area. Patients that arrive by ambulance who are in critical conditions are routed directly to the resuscitation area, while ill patients who require their conditions to be monitored stay in the major assessment area. The ambulatory care area is for patients suffering from abdominal pain, headache, limb problems, wounds, head injuries, and facial problems (amongst all other ambulant patients). 


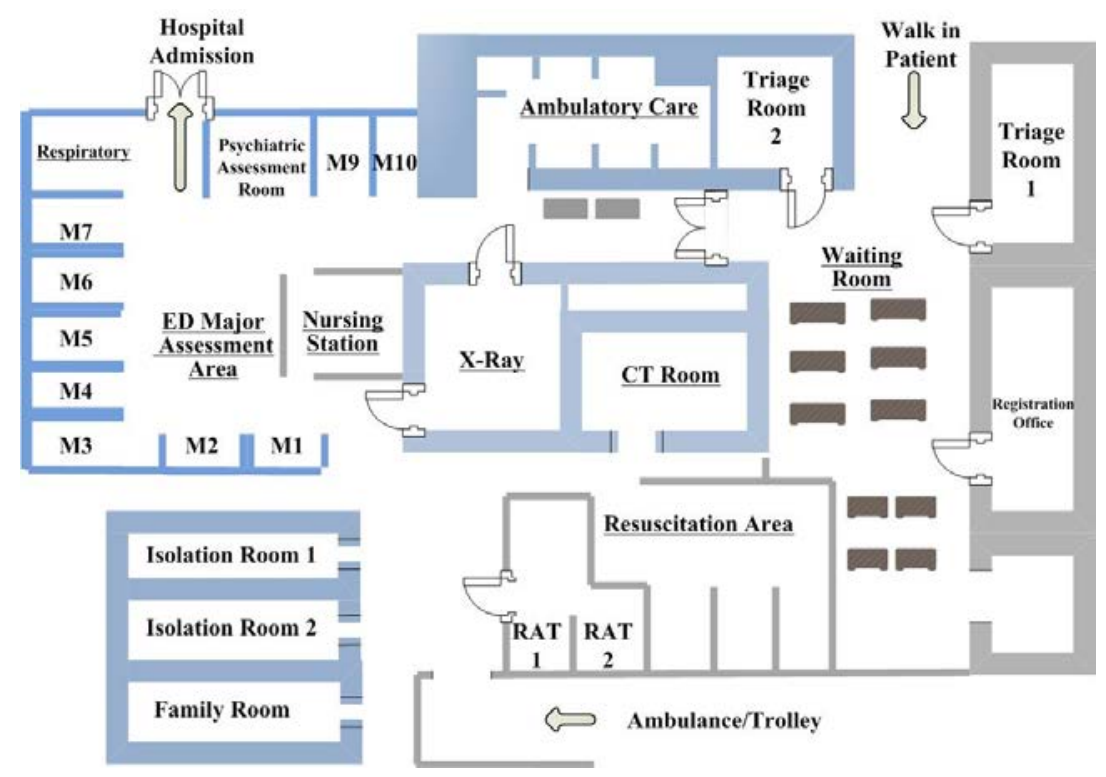

Figure 2 ED physical layout and main areas

\subsection{ED Staff}

As a 24hr department, the ED has eleven nurses during the day and nine nurses at night which collectively are divided into six types of nurses; Advanced Nurse Practitioner (ANP), triage nurse, resuscitation nurse, respiratory nurse, majors/minors nurse, and healthcare assistant. Physicians (excluding the 3 Consultants who provide shop floor cover between 9-5 or $8-8$ with $24 / 7$ on-call provision), referred to as non-consultant hospital doctors (NCHD), are divided into three types: registrar/specialist registrar (i.e., receiving advanced training in a specialist field of medicine in order eventually to become a consultant), Senior House Officer (SHO) (i.e., a junior doctor undergoing training within a certain speciality), and intern that are distributed as follows when the roster allows: three registrars per day with a $10 \mathrm{hr}$ shift starting at $8 \mathrm{am}, 12 \mathrm{pm}$, and $10 \mathrm{pm}$; two interns with a one shift per day from $8 \mathrm{am}$ to $5 \mathrm{pm}$ Monday to Friday; and overlapping shifts of SHOs during the day to make it possible to have more than one SHO at specific time (i.e. from 2 to 6 SHOs during the day).

\subsection{Key Performance Indicators Selection}

Following repeated visits to the ED and interviewing the senior management team, the ED manager has identified two main key performance areas: patient throughput and ED efficiency. The performance measures for patient throughput are the average waiting time and average length of stay (LOS), while for ED efficiency they are; ED productivity, resource utilisation and layout efficiency. Figure 3 shows the breakdown of the key performance indicators (KPIs) according to the ED senior managers. 
ED Performance

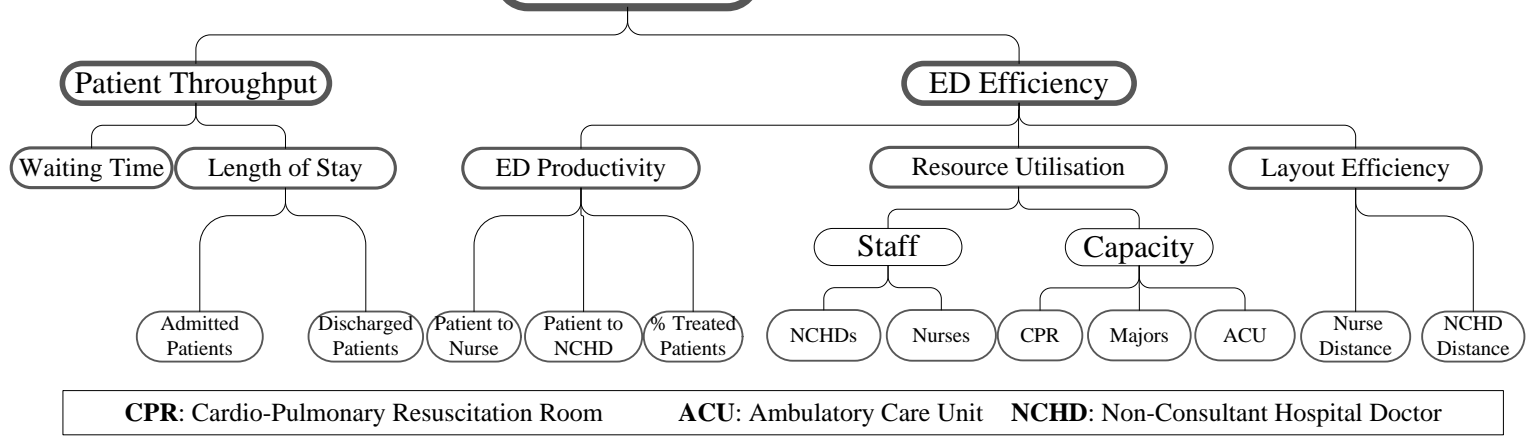

Figure 3 Key performance indicators for the ED

\subsection{Patient Flow Analysis}

Upon arrival at the ED and registration, walk-in patients (self-referral or GP referral) remain in the waiting area to be triaged (Figure 4).

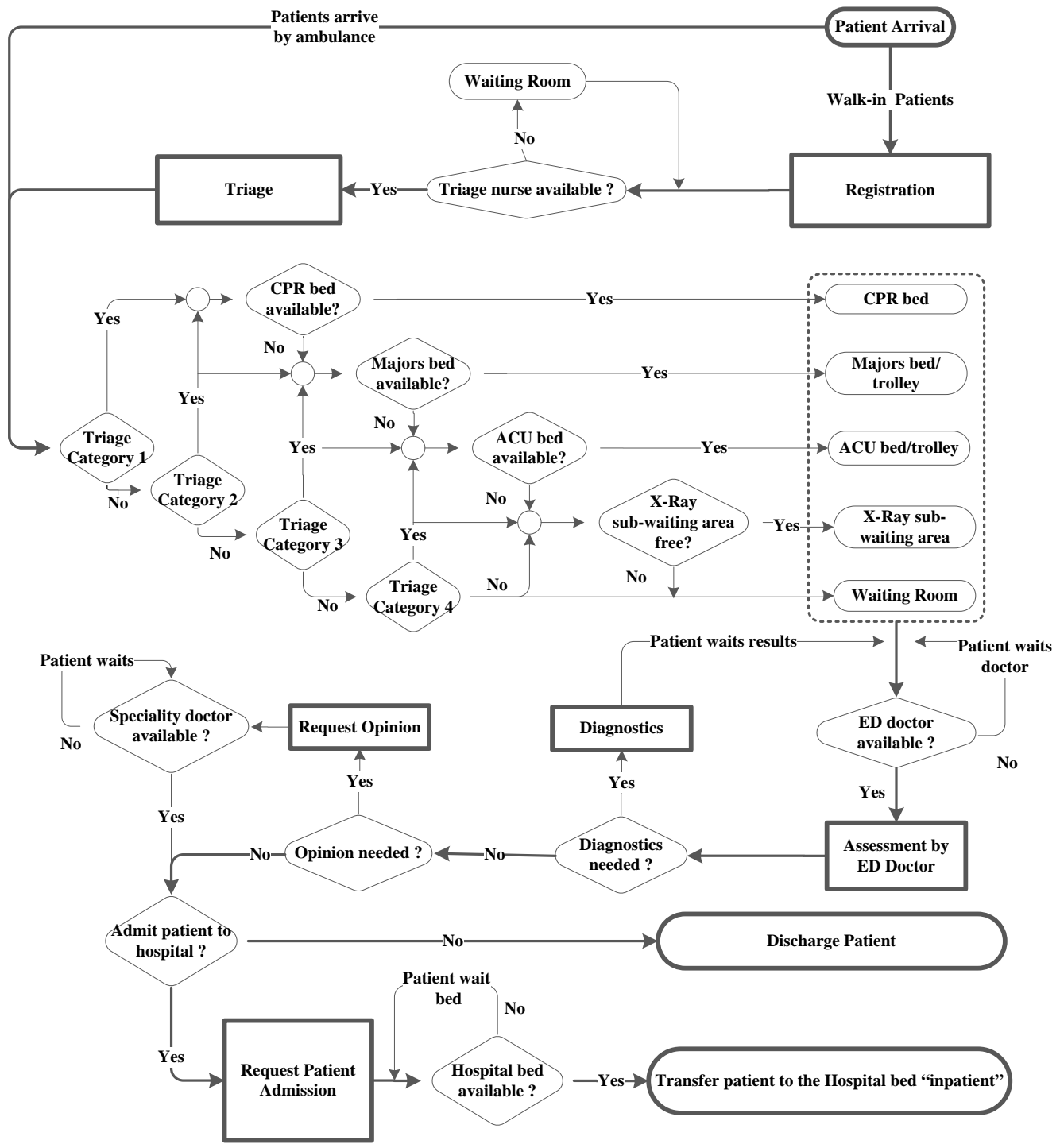

Figure 4 A detailed flowchart for the patient flow in the ED 
When a patient's name is called, depending on triage staff availability, the patient is assessed by a triage nurse. Based on patient condition and triage assessment, each patient is assigned a clinical priority (triage category) according to the Manchester Triage System (MTS) that is widely used in UK, Europe, and Australia (Cronin, 2003). The MTS uses a five level scale for classifying patients according to their care requirements; immediate, very urgent, urgent, standard, and non-urgent. Once a triage category is assigned, the patient may be sent back to the waiting room until a bed or trolley is available in an appropriate treatment area, based on the type and intensity of their care requirements. The patient's waiting time depends on the triage category of patient and the availability of both medical staff (i.e. ED physician or ANP) and empty trolleys, which are a prerequisite for a complete and accurate assessment. Following the patient's assessment by an ED clinician, a decision is made, either the patient is to be discharged or admitted to the hospital. These are the primary care stages which are relevant for all patients, whether they are discharged from or admitted to hospital. Secondary patient stages are those steps involved in the care of some but not all patients such as diagnostics (e.g. X-Ray and blood test), and second patient assessment by ED doctor. Opinion may be requested by ED staff from a medical/surgical speciality doctor to confirm that a patient should be admitted or to obtain advice on the best possible treatment for the patient who is to be discharged.

\subsection{ED Process Mapping}

Based on the analysis of patient flow through the ED, a detailed flowchart is built which highlights the common processes and decision points involved in the care of patients through the ED. Each ED process is then broken down into smaller sub-functions with key resources (e.g. staff and medical equipments) at each care stage are identified and detailed using IDEF0 (Colquhoun, Baines, \& Cro, 1993). IDEF0 is a powerful tool for modelling complex systems which allows users (e.g. ED managers, decision makers, system analysts) to comprehensively understand the system through modelling decisions, actions, and processes in a hierarchical form. Such organizational strategy allows the system to be easily refined into more detail until the model is as descriptive as necessary for the decision maker (S. H. Kim \& Jang, 2002). The top level of the developed IDEF0 model is shown in Figure 5. The main unit of an IDEF0 model is an activity block that describes the main function of the process. ICOMs (Input, Control, Output and Mechanism) are represented by horizontal and vertical arrows. Process control (top arrow) can be patient information (e.g. arrival time, triage category, and presenting complaint), safety regulations, or national/international standards whereas process 
mechanisms are usually the agents/resources which facilitate the activity (e.g. ED physicians, nurses, and physical beds/trolleys).

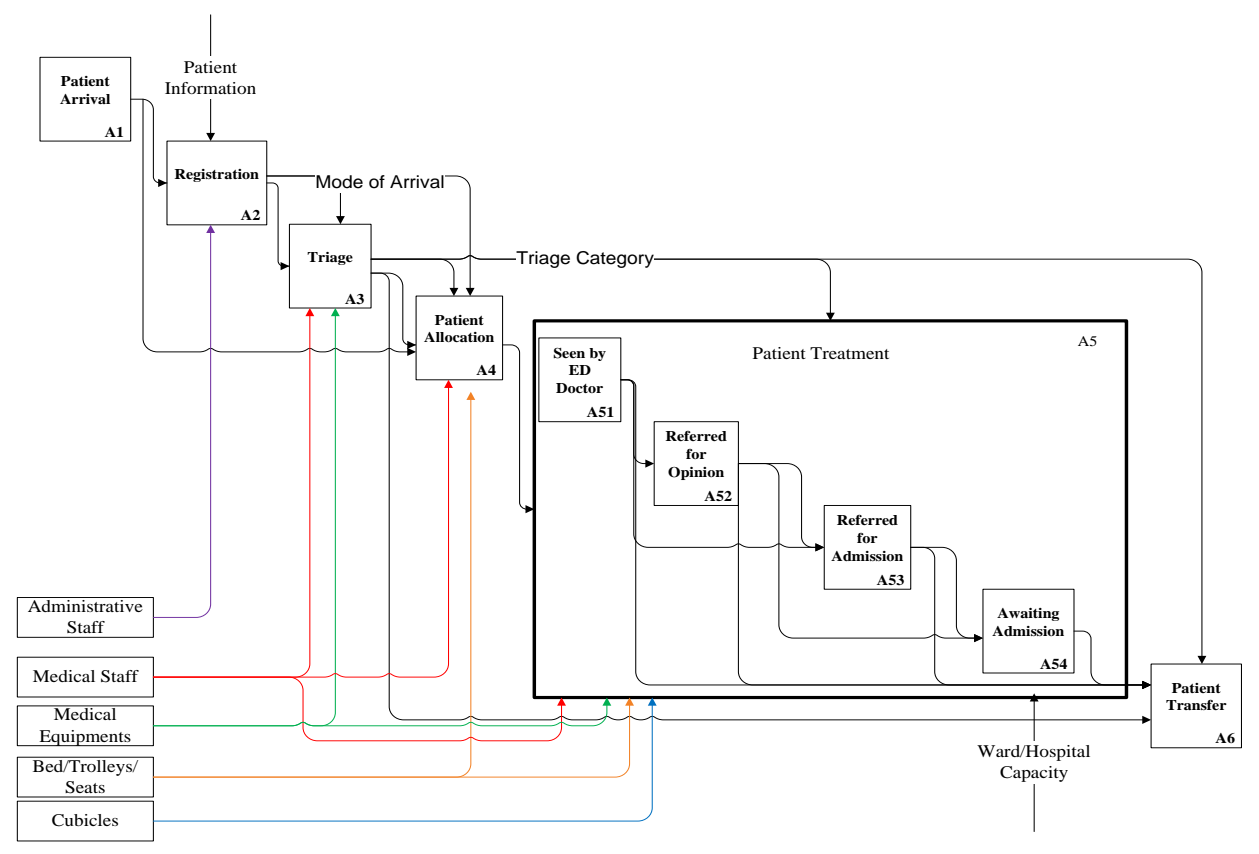

Figure 5 Process mapping of main ED process using IDEF0

The utilization of IDEF for process modeling has not only improved the quality of simulation models but also it enhanced the communication levels among decision makers and the staff (e.g., doctors and nurses) through modeling the underlined work flow, decision points, and processes in a hierarchical form. This hierarchical structure kept the model scope within the boundaries represented by breaking down processes into smaller sub-functions. Such organizational strategy allowed the system to be easily refined into more details until the model is as descriptive as necessary for the decision maker.

\subsection{Empirical Data Analysis}

The analysis of empirical data is essential in developing a robust simulation model that considers the time features of the intended system in terms of demand volume and patterns. A thorough analysis of data enables the discovery of different type of patterns (i.e., clustering) that are essential to reduce the complexity of the simulated system in terms of patient groupings and patient allocation and routing analysis. This valuable information is needed to build a comprehensive and representative dynamic model for the underpinned healthcare system. Historical patients records have been gathered for the ED information system during a 16-month period provided by hospital managers with a total of 59,986 anonymous patient records. Each patient record is described by the following patient-level variables: (1) triage category assigned to patient, (2) patient presenting medical complaint, (3) 
mode of patient arrival, (4) patient attend date/time, (5) patient triage date/time, (6) date/time patient seen by doctor, and (7) whether the patient left without seen, discharged, or admitted to the hospital. We analysed patients records to extract qualitative information about patients arrival pattern, patient grouping and allocation, and routing information. Patients were grouped based on their triage category. Urgent patients (triage category 3) represent the largest group of new attendees to the ED annually (58\% average) who are presented to the ED with a wide range of medical complains and aging conditions. Patient Placement for each patient group through ED treatment areas along with the arrival mode is summarized in (Table 1).

Table 1 Input settings for different control parameters

\begin{tabular}{cccc}
\hline \multirow{2}{*}{ Triage Category } & \multirow{2}{*}{ \% of Patients } & \multicolumn{2}{c}{ Mode of Arrival } \\
\cline { 3 - 4 } & & Walk-in & Ambulance \\
\hline $\mathbf{1}$ & $1.1 \%$ & $5 \%$ & $95 \%$ \\
$\mathbf{2}$ & $16.5 \%$ & $40 \%$ & $60 \%$ \\
$\mathbf{3}$ & $58 \%$ & $61 \%$ & $39 \%$ \\
$\mathbf{5}$ & $23.9 \%$ & $81 \%$ & $19 \%$ \\
\hline
\end{tabular}

For each patient group, an estimation of patient arrival distribution is used to replicate the arrival pattern in the simulation model. From the simulation perspective, the inter-arrival data is required, not the arrival time, which describe the time delay between two consecutive patient arrivals. To do so, the difference between the arrival times of patients was obtained for each group. These inter-arrival times were then grouped into time slots where the relative frequency (i.e., percentage) of each time slot was accumulated and represented in a histogram (see Figure 6a). This was followed by the determination of a fitted distribution for each inter-arrival histogram. For example, Figure $6 \mathrm{~b}$ shows different possible distributions for the inter-arrival time for "Urgent” patient group.

a) Inter-arrival Time Density

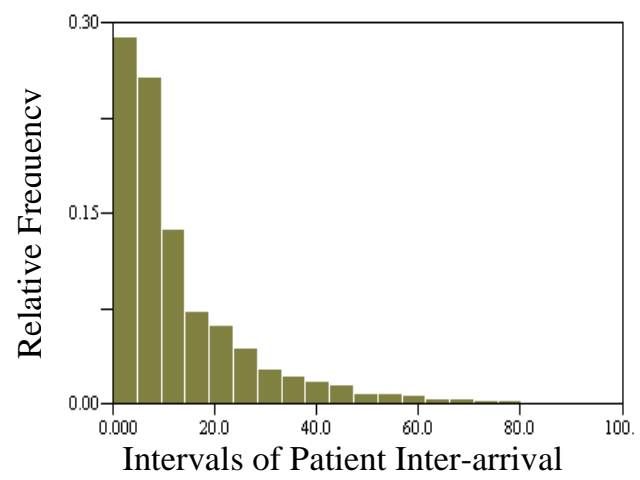

b) Fitted Density for Inter-arrival

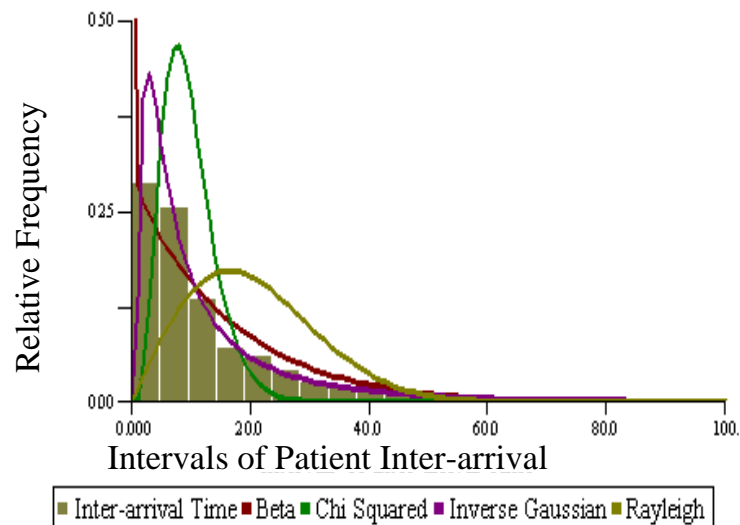

Figure 6 Relative frequency diagram - urgent patients 
The best fit distribution was then determined for each patient group and validated by using Kolmogorov Smirnov goodness of fit test with a $5 \%$ significance level. Regarding patient allocation data, Table 2 shows the analysis of the allocation of patients within the ED. Based on that analysis, the ED staff failed to fully implement the recommendations of the MTS concerning the disposition of patients, which is due to the overcrowding of the ED. For example, $88 \%$ of immediate patients are seen in the resuscitation room and $9 \%$ in the majors' cubicles, while only $40 \%$ percent of very urgent patient are seen in inappropriate assessment areas. Moreover, due to the overcrowding status of the ED, the majority of standard and nonurgent patient are assessed and treated in inappropriate areas (e.g., chairs) or wait in waiting areas.

Table 2 Analysis of patient allocation within the emergency department

\begin{tabular}{rccccc}
\hline \multirow{2}{*}{ ED Areas } & \multicolumn{4}{c}{ Triage Category } \\
\cline { 2 - 7 } & IMM & VURG & URG & STD & NURG \\
\hline Resuscitation Room & $88 \%$ & $25 \%$ & $2 \%$ & $0 \%$ & $0 \%$ \\
Majors Area & $9 \%$ & $15 \%$ & $8 \%$ & $1 \%$ & $0 \%$ \\
\hline Ambulatory Care Unit & $0 \%$ & $12 \%$ & $10 \%$ & $20 \%$ & $11 \%$ \\
Majors Chairs & $0 \%$ & $7 \%$ & $6 \%$ & $1 \%$ & $1 \%$ \\
Rapid Assessment Triage & $3 \%$ & $12 \%$ & $7 \%$ & $2 \%$ & $2 \%$ \\
Waiting Room & $0 \%$ & $14 \%$ & $56 \%$ & $74 \%$ & $85 \%$ \\
X-Ray Sub-Wait Area & $0 \%$ & $15 \%$ & $12 \%$ & $4 \%$ & $1 \%$ \\
\hline
\end{tabular}

IMM: Immediate

VURG: Very Urgent

URG: Urgent

STD: Standard

NURG: Non-Urgent

\section{Simulation Model Development and Validation}

\subsection{Model Construction}

Based on the ED business process model, the designed BSC, and the empirical data analysis, a comprehensive simulation model for the ED was constructed. Modules of the simulation model were connected to resemble the ED business process model, where blocks are connected similar to the conceptual flow chart, which eases the model construction phase. Accordingly, the top-level of the simulation model defines the overall model structure, where sub-level blocks containing additional modules with more details. Object-oriented programming was used to customize pre-defined block for constructing the ED simulation model. A database was used to save the measured KPIs after each simulation run (i.e., replicate), followed by exporting the populated BSC in a tabular form for future analysis and validation. 


\subsection{Verification \&Validation}

To reduce the model development cycle time and to increase the confidence in the simulation model results, the verification and validation were carried out all the way through the development phases of the ED simulation mode. After each model development phase, the model was verified and validated with respect to other previously completed phases. For the verification process, the model logic is verified to ensure that patients follow the correct care path as expected. This was achieved by visual tracking of patients using animation and by checking intermediate output values such as queue lengths and waiting times between processes. The conceptual model had been documented and validated by circulating the document among ED senior managers and senior nursing staff. This is crucial to ensure that the logic of the model and ED activities is correct. All distributions determined from the data and used in the model were validated by using Kolmogorov Smirnov goodness of fit test with a $5 \%$ significance level (Massey, 1951). The final results of the simulation model have been validated using three techniques; face validation, comparison testing, and hypothesis testing. Face Validation is performed by interviewing ED senior managers and nursing staff in order to validate the final results of the simulation model. The second approach is 'Comparison Testing' which done by comparing the output of the simulation model with the real output of the system under identical input conditions (Balci, 1997). Three main KPIs are used in this approach; average waiting time (seen by doctor response), average LOS for discharged patients, and average LOS for admitted patients. Besides the overall average for all patients, each KPI has been also detailed for 3 patient categories; VURG, URG, and STD. Based on the comparison testing approach, the deviation between actual and simulated results for the selected KPIs range from $1 \%$ to $9 \%$ with an average of only $5 \%$ deviation (Figure 7 ).

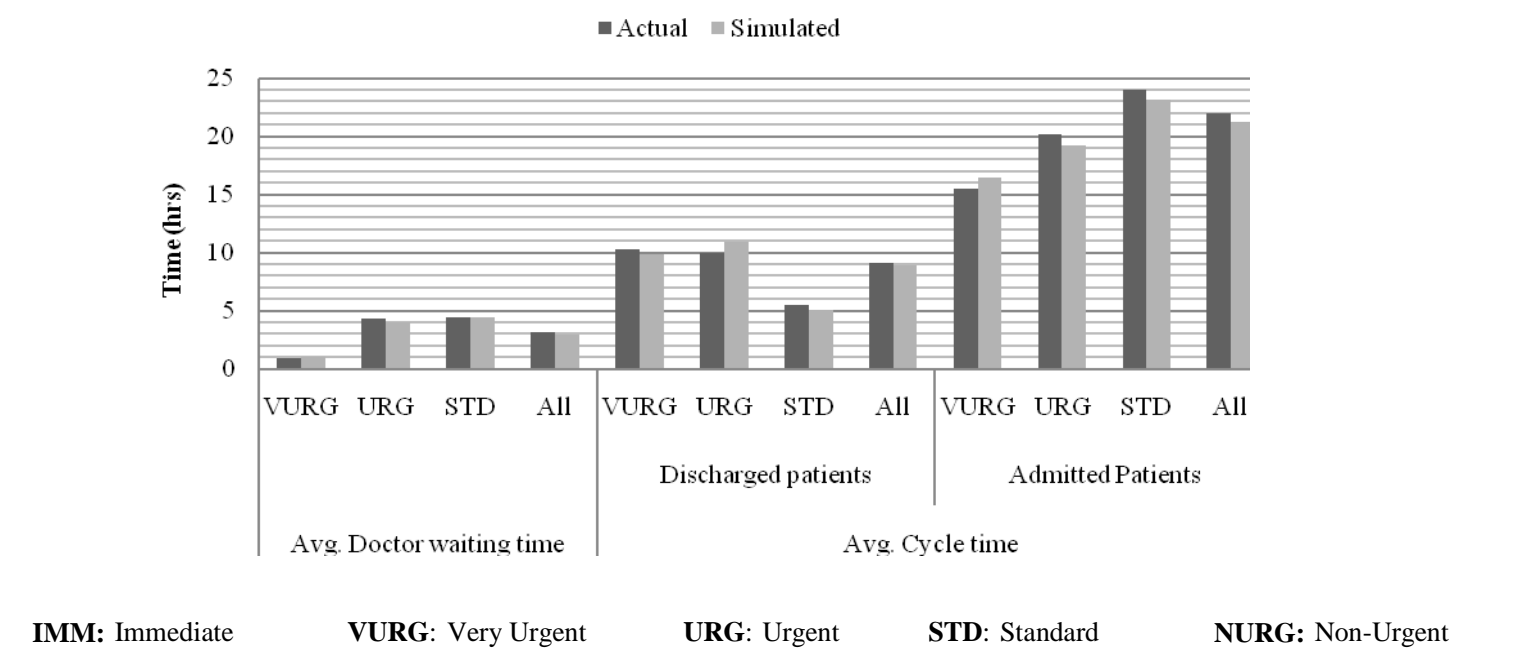

Figure 7 Validation of simulation results against actual data 


\section{Stakeholders Engagement}

The role that hospital managers and staff played was vital to the success of the project. Their level of engagement (Figure 8) at the beginning of the project was exclusive where the problem formulation and data collection phase was initiated by setting up interview sessions with the ED senior managers (two ED consultants and two nursing managers) where deep insights about the current challenges they face in managing their department were obtained. The current awareness of business process management methods (e.g., simulation modeling, multi-criteria decision analysis, and optimization) was also a key topic in the discussions and interviews. A better understanding for healthcare processes, activities, challenges, and variables was then acquired with valuable insights of the challenges in the decision making process.

The interviews helped to develop significant inputs that critically supported the development and validation phases of the proposed framework. This was followed by constructing a focus group of ED doctors and nurses for discussing issues such as general patient care paths, categories of patients and their complexities, and resources availability and capacity issues. Meanwhile, a number of interviews with ED senior managers have been taken place to discuss the performance measures. Incorporating these measures at that stage was very useful for developing the balanced scorecard for the ED and setting the objectives of the simulation model (i.e., the simulation output). Concurrently, a focus group for historical data collection was formed to discuss issues related to electronic patients records, existing information systems, and data entry procedures. That focus group included members from the information system department in the partner hospital. The discussions with that focus group was supported by a close observation of the data entry procedures through the patient journey through the ED and by a series of short interviews with the ED staff (e.g. registration staff, triage nurses, and physicians).

Project Timeline

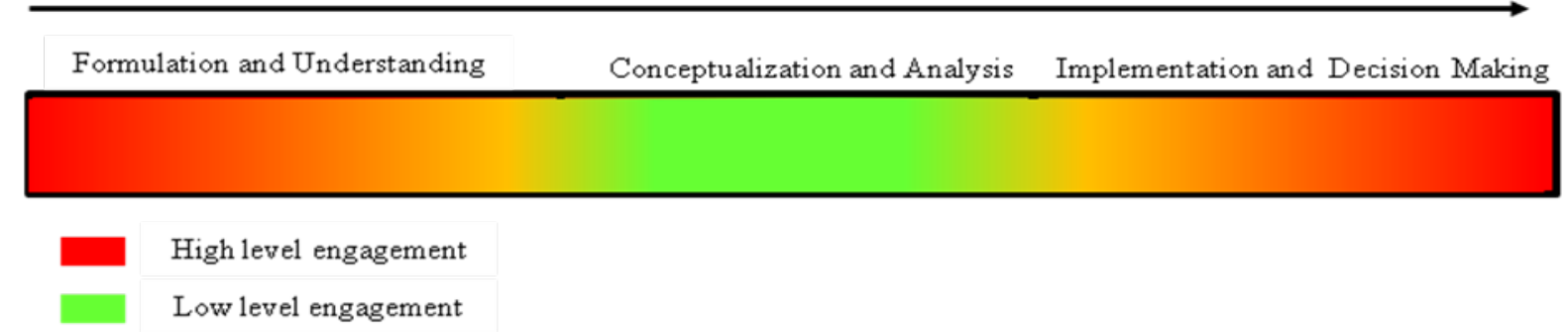

Figure 8 Engagement levels of the stakeholders during the development of the proposed framework 
Upon the completion of that stage, we started the conceptual model phase where the main ED processes were mapped and detailed into a conceptual process model using IDEF modeling languages. For the validation of the ED conceptual model, it was circulated among the senior managers and the patient flow focus group, where it was then refined through another cycle of interviews and observations. While developing the simulation model, the level of staff engagement has been decreased while building the simulation model. Upon the completion of this stage, a number of interviews with the ED senior managers were established in order to validate the simulation model (i.e. simulation base-line). Subsequently, senior managers suggested a number of scenarios to be evaluated using the simulation model.

These scenarios were suggested by the ED senior managers to evaluate the intended new extension of the hospital which will include rebuilding of key parts of the hospital including the ED. Expanding the capacity of the ED may eventually necessitate a corresponding increase in the staffing levels. Therefore, the hospital managers and the planners of the new ED express their interest to evaluate the effect of capacity expansion and increasing the staffing levels against the effect of unblocking critical performance bottlenecks such as the access block from the ED to the hospital. During the experimentation phase, the preference of the ED manager regarding the KPIs was collected and used to build the preference model and to evaluate the potential scenarios.

\section{Experimentation and Scenario Analysis}

\subsection{Scenario Design}

The simulation scenarios tested were the impact of variation in medical staffing, increasing clinical assessment space and finally assessing the impact of incorporating a 'zero-tolerance' policy regarding exceeding the national 6-hour boarding time (i.e., length of stay). According to the ED managers, the goal of the 'zero-tolerance' policy is to assess the performance of the ED if the average LOS of patients complies with the HSE 6hrs target. The importance of this assumption was emphasized by the senior hospital decision makers to identify the real factors that contribute the unacceptable overcrowding status of the current ED; inappropriate physical space, insufficient staffing levels, or operational difficulties beyond the direct control of the ED. This scenario is implemented in the simulation model by dismissing patients from the ED model who are waiting to be admitted to the hospital and their LOS exceeds 6hrs. The rationale beyond this is that hospitals can provide a short stay unit, with an appropriate capacity, for patients who are waiting to be admitted but there are no available 
beds in the hospital. Therefore, distinct study scenario variables (Table 3) were added to the simulation model and run for a 3 month continuous blocks. The three months was chosen by the ED manager for the stability of ED staffing levels offer this period.

Table 3 Simulation variables for base scenario and scenario 1, 2, and 3

\begin{tabular}{lccc}
\hline & \multicolumn{3}{c}{ Control variables } \\
\hline & $\begin{array}{c}\text { Admission } \\
\text { blockage }\end{array}$ & $\begin{array}{c}\text { Physical capacity } \\
\text { (number of trolleys) }\end{array}$ & $\begin{array}{c}\text { Additional } \\
\text { physician shift }\end{array}$ \\
$\begin{array}{l}\text { Base Scenario } \\
\begin{array}{l}\text { Scenario 1 } \\
\text { (no admission blockage / Zero-tolerance) }\end{array}\end{array}$ & Nos & 12 & - \\
$\begin{array}{l}\text { Scenario 2 } \\
\text { (increasing number of trolleys by 50\%) }\end{array}$ & Yes & 12 & - \\
$\begin{array}{l}\text { Scenario 3 } \\
\text { (adding one SHO shift over night) }\end{array}$ & Yes & 18 & - \\
\hline
\end{tabular}

The principle variables introduced were increased clinical assessment capacity (extra 6 trolley cubicles), increased clinical assessors (1 Senior House Officer shift at night), and absolute compliance with the national 6 -hour admission target for ED boarders (i.e., zerotolerance). These scenarios were selected based on the discussion in previous sections.

\subsection{Result Analysis}

Moving patients, who are waiting to be admitted, to a short stay unit or improving the admission/discharge cycle within the hospital (i.e., scenario 1) has resulted in a significant decrease in admitted patients LOS from $21.3 \mathrm{hrs}$ to $7.75 \mathrm{hrs}$ and $49 \%$ decrease in the average distance travelled by nurses (Table 4). This is because ED resources that were utilised by patients awaiting admission have been made available for other ED patients. For example, physical beds and trolleys that were occupied by patients waiting admission are available for new emergency patients, especially acute patients. Moreover, nursing staff that were frequently monitoring patients in critical medical conditions in corridors or trolleys can be reallocated to more pressurised areas in the ED. Consequently, upon their arrival, patients are seen by an ED clinician or wait inside the ED. First, patients' waiting time decreases, however, the waiting time of patients waiting to be seen by clinician increases gradually as more patients arrive. This is because the staffing level is the same and there are no more servers (i.e. staff) for incoming patients. Scenario 1 resulted in shifting the bottle neck from the waiting room to inside the ED. As a result, the average waiting time of patients, particularly less acute patients, waiting to be seen by physician increased by $15 \%$ and consequently the average LOS of discharged patients has increased to $9.78 \mathrm{hrs}$. 
Table 4 Simulation results of scenario 1, 2, and 3

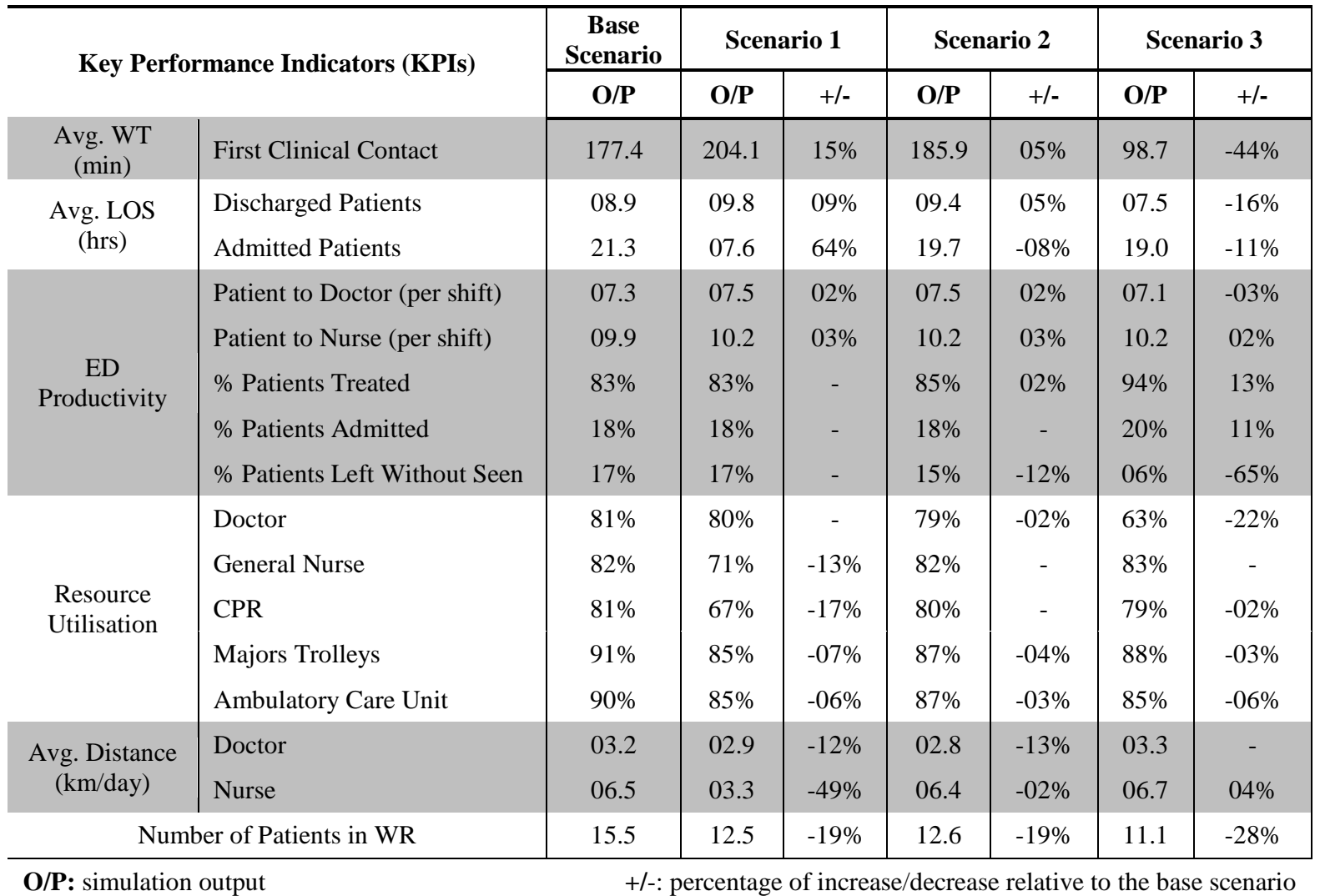

Increasing the physical space by 50\% (i.e. adding 6 trolleys/beds) will decrease the number of patients in the waiting room, though the number of admitted patients will increase by $3 \%$. The effect will be cascaded back through the ED progressively with more patients waiting on trolleys to be admitted to the hospital. As a result, there will be no space left to meet the timely needs of the next patients who need emergency care; the average waiting time increase by $5 \%$ and the average LOS run up to $9.38 \mathrm{hrs}$. On the other hand, adding one physician (i.e. SHO doctor) from 9pm to 7am will reduce the queue length in the waiting room that keeps building up over the night time (especially weekends). Subsequently, the average waiting time of patients will shorten by $44 \%$ (98.68mins) and the percentage of treated patients will increase to $94 \%$. Nevertheless, the average LOS of patients is still beyond the national metric (6hrs compared to 7.53hrs for discharged patients and 19hrs for admitted patients). Following the discussion of the results of these scenarios, it was clear for the hospital senior decision makers that investing in improving the admission/discharge cycle within the whole hospital is a more effective and practical strategy. However, they expressed their interest to explore the potential benefits of all possible combinations of the three basic scenarios (Table 5). 
Table 5 Simulation settings for scenario 4, 5, 6, and 7

\begin{tabular}{lccc}
\hline & \multicolumn{3}{c}{ Control variables } \\
\hline & $\begin{array}{c}\text { Admission } \\
\text { blockage }\end{array}$ & $\begin{array}{c}\text { Physical } \\
\text { capacity }\end{array}$ & $\begin{array}{c}\text { Additional } \\
\text { physician shift }\end{array}$ \\
\hline $\begin{array}{l}\text { Scenario 4 } \\
\text { (scenario 1 \& scenario 2) }\end{array}$ & No & 18 & - \\
$\begin{array}{l}\text { Scenario 5 } \\
\text { (scenario 1 \& scenario 3) }\end{array}$ & No & 12 & $\begin{array}{c}1 \text { SHO } \\
\text { [9pm to 7am] }\end{array}$ \\
$\begin{array}{l}\text { Scenario 6 } \\
\text { (scenario 2 \& scenario 3) }\end{array}$ & Yes & 18 & $\begin{array}{c}1 \text { SHO } \\
\text { [9pm to 7am] } \\
1 \text { SHO } \\
\text { Scenario 7 } \\
\text { (scenario 1 \& scenario 2 \& scenario 3) }\end{array}$ \\
\hline
\end{tabular}

The effect of scenario 1 on the ED performance is greater than that by adding more ED beds or having an additional physician. Moreover, when this solution is combined with one or both other solutions, the performance is improved significantly, as shown in Table 6 .

Table 6 Simulation results of scenario 4, 5, 6, and 7

\begin{tabular}{|c|c|c|c|c|c|c|c|c|c|c|}
\hline \multirow{2}{*}{\multicolumn{2}{|c|}{ Key Performance Indicators (KPIs) }} & \multirow{3}{*}{$\begin{array}{c}\begin{array}{c}\text { Base } \\
\text { Scenario }\end{array} \\
\mathbf{O} / \mathbf{P} \\
177.4 \\
\end{array}$} & \multicolumn{2}{|c|}{ Scenario 4} & \multicolumn{2}{|c|}{ Scenario 5} & \multicolumn{2}{|c|}{ Scenario 6} & \multicolumn{2}{|c|}{ Scenario 7} \\
\hline & & & \multirow{2}{*}{$\frac{\mathbf{O} / \mathbf{P}}{141.3}$} & \multirow{2}{*}{$\frac{+/-}{-20 \%}$} & \multirow{2}{*}{$\frac{\mathbf{O} / \mathbf{P}}{110.8}$} & \multirow{2}{*}{$\frac{+/-}{-38 \%}$} & \multirow{2}{*}{$\frac{\mathbf{O} / \mathbf{P}}{105.2}$} & \multirow{2}{*}{$\frac{+/-}{-41 \%}$} & \multirow{2}{*}{$\frac{\mathbf{O} / \mathbf{P}}{99.3}$} & \multirow{2}{*}{$\frac{+/-}{-44 \%}$} \\
\hline $\begin{array}{l}\text { Avg. WT } \\
\text { (min) }\end{array}$ & First Clinical Contact & & & & & & & & & \\
\hline \multirow{2}{*}{$\begin{array}{c}\text { Avg. LOS } \\
\text { (hrs) }\end{array}$} & Discharged Patients & 08.9 & 08.5 & $-05 \%$ & 07.5 & $-17 \%$ & 07.5 & $-16 \%$ & 07.4 & $-18 \%$ \\
\hline & Admitted Patients & 21.3 & 06.9 & $-68 \%$ & 06.6 & $-69 \%$ & 18.8 & $-12 \%$ & 06.4 & $-70 \%$ \\
\hline \multirow{5}{*}{$\begin{array}{c}\text { ED } \\
\text { Productivity }\end{array}$} & Patient to Doctor (per shift) & 07.3 & 07.7 & $05 \%$ & 07.3 & - & 07.2 & - & 07.3 & - \\
\hline & Patient to Nurse (per shift) & 09.9 & 10.2 & $03 \%$ & 10.4 & $05 \%$ & 10.3 & $04 \%$ & 10.4 & $05 \%$ \\
\hline & $\%$ Patients Treated & $83 \%$ & $90 \%$ & $08 \%$ & $94 \%$ & $13 \%$ & $93 \%$ & $12 \%$ & $95 \%$ & $14 \%$ \\
\hline & \% Patients Admitted & $18 \%$ & $19 \%$ & $06 \%$ & $20 \%$ & $11 \%$ & $20 \%$ & $11 \%$ & $20 \%$ & $11 \%$ \\
\hline & $\begin{array}{l}\% \text { Patients Left Without } \\
\text { Seen }\end{array}$ & $17 \%$ & $10 \%$ & $-41 \%$ & $06 \%$ & $-65 \%$ & $07 \%$ & $-59 \%$ & $05 \%$ & $-71 \%$ \\
\hline \multirow{5}{*}{$\begin{array}{l}\text { Resource } \\
\text { Utilisation }\end{array}$} & Doctor & $81 \%$ & $71 \%$ & $-12 \%$ & $61 \%$ & $-25 \%$ & $63 \%$ & $-22 \%$ & $60 \%$ & $-26 \%$ \\
\hline & General Nurse & $82 \%$ & $67 \%$ & $-18 \%$ & $69 \%$ & $-16 \%$ & $83 \%$ & - & $68 \%$ & $-17 \%$ \\
\hline & $\mathrm{CPR}$ & $81 \%$ & $64 \%$ & $-21 \%$ & $62 \%$ & $-23 \%$ & $79 \%$ & $-02 \%$ & $62 \%$ & $-23 \%$ \\
\hline & Majors Trolleys & $91 \%$ & $70 \%$ & $-23 \%$ & $74 \%$ & $-19 \%$ & $83 \%$ & $-09 \%$ & $64 \%$ & $-30 \%$ \\
\hline & Ambulatory Care Unit & $90 \%$ & $75 \%$ & $-17 \%$ & $73 \%$ & $-19 \%$ & $81 \%$ & $-10 \%$ & $68 \%$ & $-24 \%$ \\
\hline \multirow{2}{*}{$\begin{array}{l}\text { Avg. } \\
\text { Distance } \\
\text { (km/day) }\end{array}$} & Doctor & 03.2 & 02.5 & $-23 \%$ & 02.9 & $-11 \%$ & 02.9 & $-11 \%$ & 02.6 & $-19 \%$ \\
\hline & Nurse & 06.5 & 02.7 & $-59 \%$ & 02.8 & $-56 \%$ & 06.5 & - & 02.5 & $-62 \%$ \\
\hline \multicolumn{2}{|c|}{ Number of Patients in Waiting Room } & 15.5 & 11.8 & $-24 \%$ & 08.2 & $-47 \%$ & 09.4 & $-39 \%$ & 05.6 & $-64 \%$ \\
\hline
\end{tabular}

O/P: simulation output

+/-: percentage of increase/decrease relative to the base scenario

As expected, scenario 7 dominates all other scenarios in terms of ED performance. As shown in Table 6, the average LOS for admitted patients is approximately 6hrs, and percentage of patients left without treatment is $5 \%$ which meet the national metric for both 
LOS and percentage of untreated patients. A multi-criteria decision analysis approach has been used to reflect the ED decision makers' preferences and to account for the tradeoffs between competing KPIs.

\subsection{A Preference Model for ED}

Based on the scenarios' results in Table 4 and Table 6, a preference model has been developed using preference ratios in multi-attribute evaluation (PRIME) (Salo \& Hamalainen, 2001). The suitability of PRIME approach to the analysis of these scenarios lies into that 1) its ability to model a hierarchical structure of criteria (value tree); and 2) it is able to handle incomplete information (uncertainty) about decision maker preferences through the use of interval-valued ratio statements (Lindstedt, et al., 2001). Based on base line scenario, and the results of the first three scenarios (Table 4), along with the simulation results of the simulation output for their combinations (Table 6), PRIME (Appendix A) was used for building the ED preference model. The imprecise preferences of the ED mangers were used to construct weighted intervals of the ED KPIs as shown in Figure 9.

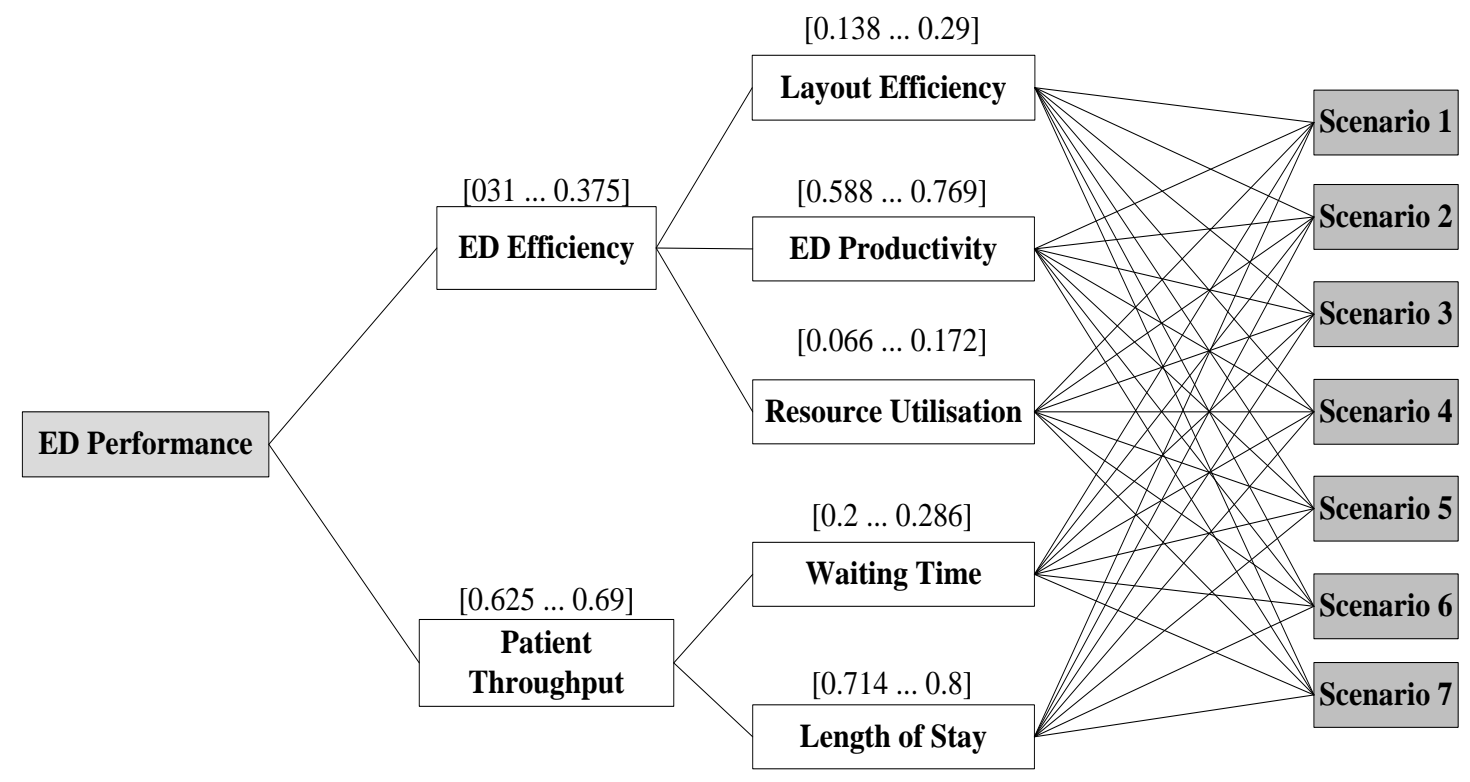

Figure 9 The value tree of the emergency department

The marginal performance of the KPIs was then aggregated using the PRIME value tree and resulted in a performance value interval for each scenario. As shown in Figure 10, the aggregate performance of ED is represented as an interval that represents the marginal gain of each scenario. For example, an increase between 38\% and 54\% in the performance is 
achieved for scenario 1 while the expansion of the physical ED capacity (scenario 2) enhanced the ED performance only by $8 \%$ to $19 \%$. The visual presentation of these value intervals of the performance of each scenario (Figure 10) has provided the senior managers with a powerful tool to interpret the simulation results and at the same time to account for their preferences. For example, by the visual inspection of value intervals for the scenarios, scenario 1 dominates both scenario 2 and 3. Consequently, any improvement strategy that will not address the access blockage (i.e. scenario 1) will not lead to the desired performance targets. Based on these insights, the hospital senior managers have prioritized improving the admission/discharge planning activities across the hospital over the other expensive solution alternatives (i.e. scenario 2 and 3).

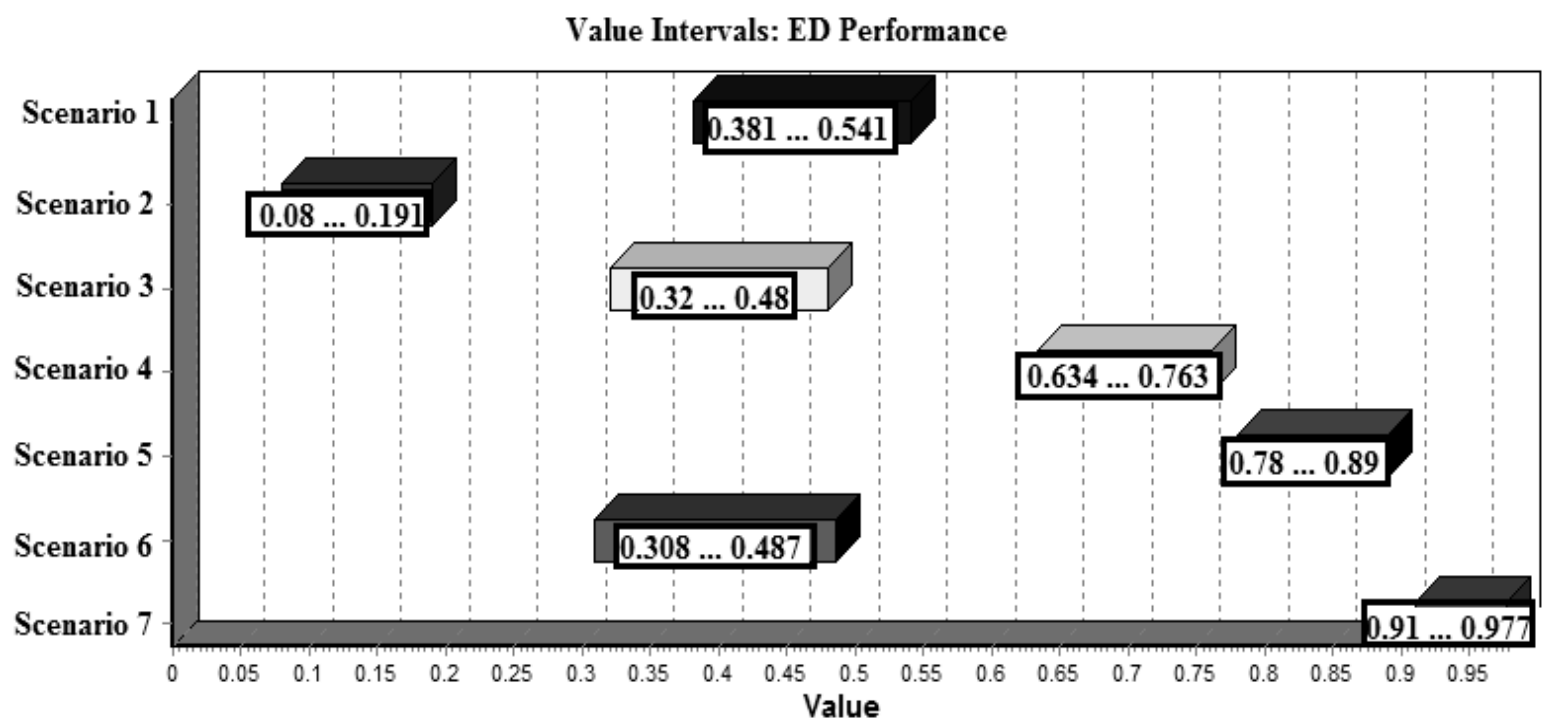

Figure 10 Value intervals for all scenarios

\section{Discussion}

The proposed framework has been well-received by the ED managers and the hospital senior decision makers and acknowledge as a sustainable tool to support their strategies. A number of factors have contributed to this positive perception from the management team. Firstly, the development of a high-level process model prior to the development of the simulation model has greatly helped in the collection of relevant information on the operation of the system (i.e. data collection) and, therefore, reduced the effort and time consumed to develop the simulation model. The utilization of IDEF for process modeling has not only improved the quality of the simulation model but also it enhanced the communication levels among decision makers and the staff (e.g., doctors and nurses) through modeling the underlined 
work flow, decision points, and processes in a hierarchical form. This hierarchical structure kept the model scope within the boundaries represented by breaking down processes into smaller sub-functions. Such organizational strategy allowed the system to be easily refined into more details until the model is as descriptive as necessary for the decision maker. Secondly, the integration between simulation modeling and balanced scorecard contributed to the alleviation of BSC limitations in terms of its measurement capabilities and the lack of inferring the causal-effect among performance measures. Further, this integration established a clear link between the strategic objectives of the organization and the daily activities within the department, which gave decision makers deep insights regarding performance bottlenecks and potential corrective plans. Finally, the combination of multi-criteria decision analysis tools along with simulation and BSC contributed significantly in the decision making process by explicitly dealing with priorities and trade-offs between different performance indicators. This was achieved by not only considering the preference of decision makers regarding the achievement levels of performance measures, but also by incorporating the imprecise and incomplete information about their preferences.

Although the proposed framework has successfully encompassed many factors that affect decision making, there is still a room to improve. The key limitation of the proposed framework is the cost factor of the decision. The study objectives set at the beginning of the project highlighted the importance of the cost element in the strategic level of decisions, however incorporating the cost element was not possible in this study due to two main reasons; (1) lack of cost related information to support the analysis phase and, (2) the variability in the cost model in various public hospital in Ireland created a high level of complexity to model the financial element. Nevertheless, there is currently a new project launched within the group to analysis the cost model in the public hospital and attempt to standardize the financial model so that analysis can be conducted. It is also worth mentioning that the output related to the staff utilization was approximated to union and confidentiality issues. To work around this, the analysis was done based on the percentage of time that the staff spent with patients and that was agreed with the ED managers. The proposed framework is also limited to discrete-event simulation (DES), other simulation and modeling methods such as system dynamics (SD) and agent-based simulation (ABS) are emerging as potential tools for analyzing the inter-connected relationships between healthcare components at the macro-level of the system. 


\section{Conclusion}

With healthcare costs continuing to rise and funds continuing to decline, there is an urge of effective process improvement methodologies to address the reported inefficiencies in healthcare delivery. Most of the existing methodologies are described by managers as lacking strategy-linked measures. Owning the fact that stakeholder's engagement is crucial, a key element in developing robust framework is working close to the process owners and teams. In this paper, a simulation-based decision support system is presented for healthcare process improvement. The framework integrates simulation with balanced scorecard (BSC) as a performance management technique which plays an important role in communicating objectives and actions between decision makers and other staff, monitoring achievements, and driving related corrective actions. Further, multi-criteria decision analysis (MCDA) tools are used to incorporate decision makers' preferences in the evaluation of these actions. The framework is demonstrated through a real-world case study in an emergency department of one of leading hospitals in Republic of Ireland.

By using the model, the ED managers were able to reveal that enforcement of the national benchmark of 6-hour boarding limit for EDs would have a significantly greater impact on reducing average length of stay for all ED patients than increasing medical staff or assessment cubicles. Access block therefore, has been shown by the model to have the highest impact on prolonged average length of stay for patients and successful strategies are available to reduce hospital access block especially in situations of ED surge and reduced hospital bed capacity. The proposed framework was helpful and well-received by the ED managers; it did directly contribute to plan the new strategies in the ED and also in the planning phase of the new ED. Moreover, the recommendations of the framework have also been considered by the executive board of the partner hospital where framework is currently used to model other hospital processes that affect the flow of patients to achieve the required alignment and coordination between hospital units.

\section{References}

Ahmed, M. A., \& Alkhamis, T. M. (2009). Simulation optimization for an emergency department healthcare unit in Kuwait. European Journal of Operational Research, 198, 936-942. 
Balci, O. (1997). Verification validation and accreditation of simulation models. In S. Andradóttir, K. J. Healy, D. H. Withers \& B. L. Nelson (Eds.), Proceedings of the 1997 Winter Simulation Conference (pp. 135-141). Atlanta, Georgia, USA.

Benneyan, J. C. (1997). An introduction to using computer simulation in healthcare: patient wait case study. Journal of the Society for Health Systems, 5, 1-15.

Brailsford, S., \& Vissers, J. (2011). OR in healthcare: A European perspective. European Journal of Operational Research, 212, 223-234.

Ceglowski, R., Churilov, L., \& Wasserthiel, J. (2006). Combining data mining and discrete event simulation for a value-added view of a hospital emergency department. Journal of the Operational Research Society, 58, 246-254.

Colquhoun, G., Baines, R., \& Cro, S. (1993). A state of the art review of IDEF0. International Journal of Computer Integrated Manufacturing, 6, 252-264.

Connelly, L. G., \& Bair, A. E. (2004). Discrete event simulation of emergency department activity: a platform for system level operations research. Academic Emergency Medicine, 11, 1177-1185.

Cronin, J. (2003). The introduction of the Manchester triage scale to an emergency department in the Republic of Ireland. Accident and Emergency Nursing, 11, 121-125.

Dittus, R. S., Klein, R. W., DeBrota, D. J., Dame, M. A., \& Fitzgerald, J. F. (1996). Medical resident work schedules: design and evaluation by simulation modeling. Management Science, 42, 891-906.

Duguay, C., \& Chetouane, F. (2007). Modeling and improving emergency department systems using discrete event simulation. Simulation, 83, 311-320.

Dyer, J. S., Fishburn, P. C., Steuer, R. E., Wallenius, J., \& Zionts, S. (1992). Multiple criteria decision making, multiattribute utility theory: the next ten years. Management Science, 38, 645-654.

Eldabi, T., Paul, R., \& Young, T. (2006). Simulation modelling in healthcare: reviewing legacies and investigating futures. Journal of the Operational Research Society, 58, 262-270.

Forero, R., Hillman, K., McCarthy, S., Fatovich, D., Joseph, A., \& Richardson, D. (2010). Access block and ED overcrowding. Emergency Medicine Australasia: EMA, 22, 119-35.

Graff, L. (1999). Overcrowding in the ED: an international symptom of health care system failure. The American Journal of Emergency Medicine, 17, 208-209. 
Harper, P., Shahani, A., Gallagher, J., \& Bowie, C. (2005). Planning health services with explicit geographical considerations: a stochastic location-allocation approach. Omega, 33, 141-152.

Ingolfsson, A., Erkut, E., \& Budge, S. (2003). Simulation of single start station for Edmonton EMS. Journal of the Operational Research Society, 54, 736-746.

Ismail, K., Abo-Hamad, W., \& Arisha, A. (2010). Integrating balanced scorecard and simulation modeling to improve emergency department performance in Irish hospitals. In B. Johansson, S. Jain, J. Montoya-Torres, J. Hugan \& E. Y“ucesan (Eds.), Proceedings of the 2010 Winter Simulation Conference (pp. 2340-2351). Baltimore, Maryland, USA.

Jun, J., Jacobson, S., \& Swisher, J. (1999). Application of discrete-event simulation in health care clinics: a survey. Journal of the Operational Research Society, 50, 109-123.

Kaplan, R. S., \& Norton, D. P. (1992). The balanced scorecard-measures that drive performance. Harvard Business Review, 70, 71-79.

Kaplan, R. S., \& Norton, D. P. (2001). Transforming the balanced scorecard from performance measurement to strategic management: part I. Accounting Horizons, 15, 87-104.

Khare, R. K., Powell, E. S., Reinhardt, G., \& Lucenti, M. (2009). Adding more beds to the emergency department or reducing admitted patient boarding times: which has a more significant influence on emergency department congestion?. Annals of Emergency Medicine, 53, 575-585.

Kim, S. C., Horowitz, I., Young, K. K., \& Buckley, T. A. (1999). Analysis of capacity management of the intensive care unit in a hospital. European Journal of Operational Research, 115, 36-46.

Kim, S. H., \& Jang, K. J. (2002). Designing performance analysis and IDEF0 for enterprise modelling in BPR. International Journal of Production Economics, 76, 121-133.

Liberatore, M. J., \& Nydick, R. L. (2008). The analytic hierarchy process in medical and health care decision making: A literature review. European Journal of Operational Research, 189, 194-207.

Lindstedt, M. R. K., Hämäläinen, R. P., \& Mustajoki, J. (2001). Using intervals for global sensitivity analyses in multiattribute value trees. In Proceedings of the 15th International Conference on Multiple Criteria Decision Making. Ankara, Turkey. 
Litvak, N., Van Rijsbergen, M., Boucherie, R. J., \& Van Houdenhoven, M. (2008). Managing the overflow of intensive care patients. European Journal of Operational Research, 185, 998-1010.

Massey, F. J. (1951). The Kolmogorov-Smirnov test for goodness of fit. Journal of the American Statistical Association, 46, 68-78.

Oddoye, J., Jones, D., Tamiz, M., \& Schmidt, P. (2009). Combining simulation and goal programming for healthcare planning in a medical assessment unit. European Journal of Operational Research, 193, 250-261.

Rosen, L. S., Harmonosky, M. C., \& Traband, T. M (2008). Optimization of systems with multiple performance measures via simulation: Survey and recommendations. Computers and Industrial Engineering, 54, 327-339.

Rowe, B. H., Bond, K., Ospina, M. B., Blitz, S., Afilalo, M., Campbell, S. G., \& Schull, M. (2006). Frequency, determinants, and impact of overcrowding in emergency departments in Canada: a national survey of emergency department directors. Academic Emergency Medicine, 13, S27.

Saaty, T. L. (1990). How to make a decision: the analytic hierarchy process. European Journal of Operational Research, 48, 9-26.

Salo, A. A., \& Hamalainen, R. P. (2001). Preference ratios in multiattribute evaluation (PRIME)-elicitation and decision procedures under incomplete information. IEEE Transactions on Systems, Man and Cybernetics, Part A: Systems and Humans, 31, 533-545.

Samaha, S., Armel, W. S., \& Starks, D. W. (2003). The use of simulation to reduce the length of stay in an emergency department. In S. Chick, P. J. Sánchez, D. Ferrin \& D. J. Morrice (Eds.), Proceedings of the 2003 Winter Simulation Conference (Vol. 2, pp. 1907-1911), New Orleans, Louisiana, USA.

Saunders, C. E., Makens, P. K., \& Leblanc, L. J. (1989). Modeling emergency department operations using advanced computer simulation systems. Annals of Emergency Medicine, 18, 134-140.

Schafermeyer, R. W., \& Asplin, B. R. (2003). Hospital and emergency department crowding in the United States. Emergency Medicine, 15, 22-27.

Sinreich, D., \& Jabali, O. (2007). Staggered work shifts: a way to downsize and restructure an emergency department workforce yet maintain current operational performance. Health Care Management Science, 10, 293-308. 
Stahl, J. E., Rattner, D., Wiklund, R., Lester, J., Beinfeld, M., \& Gazelle, G. S. (2004). Reorganizing the system of care surrounding laparoscopic surgery: a costeffectiveness analysis using discrete-event simulation. Medical Decision Making, 24, 461-71.

Thorwarth, M., Arisha, A., \& Harper, P. (2009). Simulation model to investigate flexible workload management for healthcare and servicescape environment. In M. D. Rossetti, R. R. Hill, B. Johansson, A. Dunkin \& R. G. Ingalls (Eds.), Proceedings of the 2009 Winter Simulation Conference (pp. 1946-1956). Austin, Texas, USA.

Vasilakis, C., Sobolev, B., Kuramoto, L., \& Levy, A. (2006). A simulation study of scheduling clinic appointments in surgical care: individual surgeon versus pooled lists. Journal of the Operational Research Society, 58, 202-211.

Voelker, K. E., Rakich, J. S., \& French, G. R. (2001). The balanced scorecard in healthcare organizations: a performance measurement and strategic planning methodology. Hospital Topics, 79, 13-24.

Wierzbicki, A. P. (2007). Modelling as a way of organising knowledge. European Journal of Operational Research, 176, 610-635.

Zelman, W. N., Pink, G. H., \& Matthias, C. B. (2003). Use of the balanced scorecard in health care. Journal of Health Care Finance, 29, 1-16. 


\section{Appendix A: Preference Ratios in Multi-Attribute Evaluation (PRIME)}

The preferences of decision maker(s) in PRIME are assumed to have an additive structure so that the overall value of an alternative (i.e., scenario) equals the sum of its attribute-specific scores,

$$
\mathrm{V}(\mathrm{x})=\sum_{\mathrm{i}=1}^{\mathrm{N}} v_{\mathrm{i}}\left(x_{\mathrm{i}}\right)
$$

where, $N$ in the number of leave nodes (i.e., twig-level KPIs that have not been decomposed into further lower level attributes in the value tree), $x_{i}$ is the achievement level of alternative $x$ with regard to the $i$-th attribute (i.e., KPI), and $v_{i}\left(x_{i}\right)$ is the single-attribute score associated with the achievement $x_{i}$ on the $i$-th attribute. The process of decision maker preference elicitation consists of two phases; score elicitation and weight elicitation. The goal of the score elicitation phase is to rank consequences ordinally with respect to the least and most preferred achievement levels $x_{i}^{0}$ and $x_{i}^{*}$ for each attribute $i$. The same process has been repeated for all the twig-level KPIs. Ordinal rankings become linear constraints of the form:

$$
v_{i}\left(x_{i}^{j}\right)-v_{i}\left(x_{i}^{k}\right)>0
$$

where $x_{i}{ }^{j}$ is more preferred than $x_{i}{ }^{k}$ in the $i$-th attribute for alternatives $j$ and $k$ respectively. Following ordinal ranking of achievement levels, further score information is obtained through interval-valued statements about ratios of value differences. The decision maker sets lower and upper bounds $[L, U]$ on the ratio between the value difference from $x_{i}^{0}$ to the achievement level $x_{i}^{j}$ and the value difference from $x_{i}^{0}$ to $x_{i}^{*}$ :

$$
L \leq \frac{v_{i}\left(x_{i}{ }^{j}\right)-v_{i}\left(x_{i}{ }^{0}\right)}{v_{i}\left(x_{i}{ }^{*}\right)-v_{i}\left({x_{i}}^{0}\right)} \leq \mathrm{U}
$$

For the weight elicitation phase, trade-off information about the relative importance of attributes is elicited through interval-valued (i.e., ratio) judgments. A reference attribute (e.g., the most important one) is selected and one hundred points are assigned to it. The decision maker is then asked to assign a range of points $[L, U]$ to the other attributes in accordance with the perceived importance of these attributes:

$$
\frac{L}{100} \leq \frac{v_{i}\left(x_{i}{ }^{*}\right)-v_{i}\left(x_{i}{ }^{0}\right)}{v_{r e f}\left(x_{\text {ref }}{ }^{*}\right)-v_{\text {ref }}\left(x_{\text {ref }}{ }^{0}\right)} \leq \frac{\mathrm{U}}{100}
$$


This process is repeated for each level in the value tree where the relative importance of KPIs is specified by the decision maker. PRIME converts the imprecise preference model then into preference synthesis structure and consists of; 1) weight intervals of the attributes, 2) value intervals for the alternatives, and 3) dominance structures and decision rules for the alternatives comparison. Weight intervals are obtained by solving the linear constraints imposed on weights (represented by lower and upper inequalities). Following weight interval calculation, value intervals are calculated for each alternative:

$$
\mathrm{V}(x) \in\left[\min \sum_{\mathrm{i}=1}^{\mathrm{N}} v_{i}\left(x_{\mathrm{i}}\right), \max \sum_{\mathrm{i}=1}^{\mathrm{N}} v_{i}\left(x_{\mathrm{i}}\right)\right]
$$

While $w_{i} \in\left[\min v_{i}\left(x_{i}^{*}\right), \max v_{i}\left(x_{i}^{*}\right)\right]$ are the linear programs that give bounds for the weight of the $i$-th attribute. The dominance structure for alternatives is then inferred. Computationally, alternative $x^{j}$ is preferred to $x^{k}$ in the sense of absolute dominance if and only if the smallest value of $x^{j}$ exceeds the largest value of $x^{k}$, i.e.,

$$
\min \sum_{\mathrm{i}=1}^{\mathrm{N}} v_{i}\left(x_{\mathrm{i}}^{\mathbf{j}}\right)>\max \sum_{\mathrm{i}=1}^{\mathrm{N}} v_{i}\left(x_{\mathrm{i}}^{\mathrm{k}}\right)
$$

